\title{
MATHEMATICAL MODEL FOR CHARTER FLIGHTS PLANNING AT AIRPORTS WITH HIGH AIR TRAFFIC VOLUME
}

The article is devoted to a problem of flight timetable planning for charter airlines if air transport is operated at airports with high air traffic volume. It is typical for such airports that air transport is subject to time slots. That means aircraft can take-off or land only in given time intervals. A suitable tool for solving such type of the task is linear programming which has been successfully employed for planning in other transport systems. In the article a mathematical model which is able to plan a flight timetable for a given set of flights is presented.

Keywords: Aircraft scheduling, linear programming, timetable planning.

\section{Introduction}

To provide reliable and regular operation of air transport all round the world, it is necessary to plan flight timetables. The flight timetables are planned not only by airlines that provide regular air transport but also airlines providing charter air transport.

Planning flight timetables is a complex and time-consuming process. The process of flight timetable preparation is usually started a year before its year of validity. The whole process is influenced by many factors. The most important factors are demands of travel agencies, operating times of airports and time slots for taking-off and landing. By means of the time slots (time intervals) airports dictate to airlines when it is possible to plan taking-off or landing at the airport. The problem of flight timetable planning can be considered to be a task of planning service of a given set of flights under different time constraints. Therefore, mathematical modelling can be successfully employed for solving the task.

The article continues in article [1]; in the article a mathematical model that enables to plan flight timetables if two time slots are available for each flight was presented. The original mathematical model was generalised as regards the number of available time slots for the flights; the improved mathematical model is described in the article. The improvement lies in the fact that for each flight any finite number of time slots can be given. Please note that the number of the available time slots can differ for the individual flights.

\section{State of the art}

Transport processes in air transport that have to be planned by airlines can be divided into several groups of elementary problems:

- Schedule design problems.

- Fleet assignment problems.

- Aircraft maintenance routing problems.

- Crew scheduling problems.

- Rostering problems.

Approaches that are used for solving the basic above mentioned problems in air transport can be divided into two basic groups - approaches that are used only for solving one of the above mentioned problems (single purpose approaches) and approaches that solve several basic problems at the same time (integrated approaches).

From the broad spectrum of publications devoted to the single purpose approaches we can mention, for example, publications $[2,3,4$ or 5$]$.

Source [2] presents a model for daily operational flight planning. The total costs of an airline including the costs of passengers caused by flight delays are used as an optimisation criterion. To solve the model the authors proposed a special fourstep heuristic.

Publication [3] is devoted to aircraft maintenance planning. The total unused legal flying time of the critical aircraft is an optimisation criterion. The publication presents a mathematical model that minimises the value of the optimisation criterion. To solve the model a metaheuristic named compressed annealing

\footnotetext{
* Vojtech Graf, Dusan Teichmann, Michal Dorda

Institute of Transport, Faculty of Mechanical Engineering, VSB - Technical University of Ostrava, Ostrava-Poruba, Czech Republic

E-mail: vojtech.graf@vsb.cz
} 
is employed, the metaheuristic is based on simulated annealing metaheuristic.

The crew scheduling problem is discussed in publication [4]. The publication is based, in contrast to other publications employing mathematical programming methods, on an unconventional approach that uses artificial neural networks.

The last publication devoted to the single purpose approaches we would like to mention is work [5]. The publication presents a model of the crew scheduling problem. The publication does not apply the model in air transport but the results can be also used for air transport. To solve the model an approach based on column generation technique is applied.

The integrated approaches include models and algorithms for solving different combinations of the above mentioned elementary problems. We can mention, for example, publications [6, 7 and 8].

An approach published in [6] is the simplest approach; the approach is sequential. It is based on sequential optimisation of the individual problems in a pre-defined order. The individual problems are solved in the order as given above in the section.

Publication [7] includes an integrated approach to the flight scheduling problem together with maintenance planning and crew scheduling within a period of a week. To solve the task a heuristic named cycle checking strategy is employed. The applied strategy splits flight plans in subsets and the subsets are matched one another. Maintenance limitations are checked when splitting the flight plans.

Publication [8] discusses an integrated approach to aircraft routing and crew scheduling. To solve the problem a three-step algorithm based on Benders' decomposition, column generation technique and dynamic constraint generation procedure is employed.

\section{Time slots in air transport}

The article deals with a modification of the mathematical model which enables to plan flight timetables in situations for which it is typical that several time slots for each flight are given. Firstly, let us discuss the time slots in air transport.

In general, time slots are defined as time intervals in which certain tasks connected with flights (taking-off or landing) or some aircraft services have to be carried out. The fact whether the airline has to make a request for the time slot or not depends on the airport where the task should be done. From the point of view of assigning the time slots, all the airports can be divided into uncoordinated, partially coordinated and fully coordinated airports. For the uncoordinated airports it is typical that the time slots are not applied for the tasks. The time slots are used for the partially or fully coordinated airports. For such airports high air traffic volumes are typical. The partially coordinated airports can apply the time slots only for some days or seasonally. The fully coordinated airports assign the time slots to the airlines during the whole year; that means each airline needs a free time slot for taking-off or landing at the airport.

Each airport can employ several types of the time slots. We can have the time slots for arrivals, departures, using passenger boarding steps or ramps, refuelling and so on. In the mathematical model presented in the article it is not necessary to consider such dividing the time slots. We can assume that each time slot used in the model corresponds to the intersection of all the above mentioned categories of the time slots. That means during the time slot the plane can land or take-off, the passengers can disembark from the plane or board the plane and the plane can be refuelled.

From the point of view of charter airlines that plan flight timetables for the whole season in advance, it is decisive that some airports (especially during the peak season or in seaside resorts) may be loaded by higher air traffic volumes. Therefore, the airline has to take into account the fact that the airport permits arrivals and departures only in the assigned time slots. Because the numbers of the time slots and their lengths may be different for the individual flights, it is necessary to incorporate the fact into the mathematical model.

Demands for the time slots are submitted to the airports in advance. The time slots at the airports are assigned to the airlines by an airport slot coordinator. After evaluations of all the demands submitted before the season the airport slot coordinator creates a preliminary flight plan to coordinate the individual time slots one another and assigns the time slots to each applicant (the charter airlines). That means the charter airline already knows its assigned time slots when planning the flight timetable and, therefore, has to use the time slots in order not to be sanctioned [9].

\section{Problem formulation and mathematical model}

Let a set $I$ of flights be given, the set contains all the flights that have to be dispatched. For each flight $i \in I$ a set $J_{i}$ is given; the set contains all the possible time slots. The time slots define time periods in which the flight $i \in I$ can depart (that means the flight has to be dispatched in one of the pre-defined time slots). Each time slot is defined by two values - a value $d_{i j}$ is the lower bound of the time slot $j \in J_{i}$ assigned to the flight $i \in I$ and a value $h_{i j}$ is the upper bound of the time slot $j \in J_{i}$ of the flight $i \in I$.

For each flight $i \in I$ its flight time $T_{i}$ is given. It corresponds to the time between taking-off and landing. A so-called preparation time is included in the model. The preparation time is a time that is needed for carrying out all tasks after landing the flight and for preparing a consecutive flight $j \in I$. In order to simplify it, the preparation time consists of three sub-times. The first subtime $\tau_{1}$ includes stopping the aircraft, placing wheel chocks, putting passenger boarding steps or ramps, connecting the 
aircraft to a ground power unit (GPU), getting off the passengers and unloading the baggage. The second sub-time depends on services which are demanded by the aircraft's operator and on the flight time of the consecutive flight. The dependence is expressed by a product $T_{j} \cdot k$, where $T_{j}$ is the flight time of the flight $j \in I$ and $k$ is a relative constant. The relative constant expresses the ratio of the flight time $T_{j}$ of the consecutive flight and the time that is needed for preparation the flight $j \in I$. The second sub-time contains cargo unloading, cleaning the aircraft, catering replenishment, cabin service (water replenishment, toilette emptying and so on), refuelling, a technical inspection and cargo loading. The third sub-time $\tau_{2}$ includes loading passengers' baggage, boarding the passengers, removing passenger boarding steps or ramps, disconnecting the ground power unit and taxiing the aircraft from a terminal to a runway.

In order to model required decisions and to create necessary logical links 3 groups of variables $t_{i}, x_{i j}$ and $z_{i j}$ are defined in the model. The variables $t_{i}$ model the departure times of the individual flights $i \in I$; the variables $t_{i}$ can take non-negative real values. The variables $x_{i j}$ model decisions about links between the flights $i \in I$ and $j \in I$. If $x_{i j}=0$, then the aircraft is not assigned to the flight $j \in I$ after serving the flight $i \in I$. If $x_{i j}=1$, then the aircraft is assigned to the flight $j \in I$ after serving the flight $i \in I$. That means both flights are served by the same aircraft in the order $i \rightarrow j$. Please note that if $x_{0 j}=1$ then a new aircraft is assigned to the flight $j \in I$. The last group of the variables $z_{i j}$ gives information which time slot $j \in J_{i}$ is chosen for dispatching the flight $i \in I$ (that means the departure time of the flight $i \in I$ lies in the interval $\left\langle d_{i j}, h_{i j}\right\rangle$ ). If $z_{i j}=0$, then the time slot $j \in J_{i}$ is not used for dispatching the flight $i \in I$. On the other hand, if $z_{i j}=1$, then the departure time of the flight $i \in I$ lies in the time slot $j \in J_{i} . P$ is a very large positive number.

Our goal is to assign the aircraft to the individual flights so that the number of the assigned aircraft is as minimal as possible. The mathematical model of the problem can be defined in the following form:

$$
\begin{array}{lc}
\min \sum_{j \in I} x_{0 j} & \\
\sum_{i \in I \cup\{0\}} x_{i j}=1 & j \in I \\
\sum_{j \in J}^{n} x_{i j} \leq 1 & i \in I \\
t_{j}-\left(t_{i}+T_{i}+\tau_{1}+T_{j} \cdot k+\tau_{2}\right) \geq P \cdot\left(x i_{j}-1\right) & i \in I, j \in I \\
\sum_{j \in J_{i}} d_{i j} \cdot z_{i j} \leq t_{i} & i \in I \\
\sum_{j \in J_{i}} h_{i j} \cdot z_{i j} \geq t_{i} & i \in I \\
\sum_{j \in J_{i}} z_{i j}=1 & i \in I
\end{array}
$$

$\begin{array}{ll}x_{i j} \in\{0,1\} & i \in I \cup\{0\}, j \in I \\ z_{i j} \in\{0,1\} & i \in I, j \in J_{i} \\ t_{i} \geq 0 & i \in I\end{array}$

Formula (1) corresponds to the optimisation criterion of the mathematical model. As written earlier in the text, we try to minimise the number of the aircraft we need to serve all the planned flights. Constraints (2) ensure that each flight $j \in I$ has to be dispatched. Constraints (3) model that only one of two possible tasks is assigned to the aircraft after serving the flight $i \in I$ - the aircraft can be assigned to the consecutive flight $j \in I$ or is idle. Constraints (4) ensure that if a consecutive flight is assigned to the aircraft, the assignment is admissible in terms of time. The term on the left side of constraint (4) equals to the departure time of the consecutive flight $j \in I$ minus the sum of the departure time of the preceding flight $i \in I\left(t_{i}\right)$, the flight time of the flight $i \in I\left(T_{i}\right)$ and the preparation time before serving the flight $j \in I\left(\tau_{1}+T_{j} \cdot k+\tau_{2}\right)$. Constraints (5) and (6) ensure the admissible departure times of the flights $i \in I$. That means the departure times $t_{i}$ have to lie in the predefined time slots $\left\langle d_{i j}, h_{i j}\right\rangle$. Constraints (7) assure that only single time slot $j \in J_{i}$ is chosen for dispatching the flight $i \in I$. Constraints (8), (9) and (10) define the domains of definition of the variables used in the model. In general, the total number of the variables of the model is equal to $m^{2} n+m^{2}+2 m$, where $m$ is the number of the planned flights and $n$ is the number of the time slots for the flight with the maximum number of the predefined time slots. The number of the constraints in the model is $m^{2} n+2 m^{2}+7 m$.

\section{Experiments}

Calculation experiments were carried out on model examples. The experiments were aimed at finding a dependence of the calculation time on the number of the planned flights and the length of the pre-defined time slots. In addition, we also tried to find out solvability limits of the mathematical model - to estimate for how many flights the model is able to find an optimal solution within a given time limit. In total 39 optimisation calculations were carried out with the model. All the experiments were run on a student (demo) version of optimisation software Express-IVE [10]. To run the experiments we employed a personal computer with processor AMD-8300 Eight-Core $3.3 \mathrm{GHz}$ and 8GB RAM.

For each flight $i \in I$ its flight time $T_{i}$, the length of the time slots and their bounds $d_{i j}, h_{i j}$ are known. A summary of all the values is provided in Table 1. The length of the time slots was not constant during the experiments. For the first group of the experiments the length was 5 minutes (see Table 1), for the 


\begin{tabular}{|c|c|c|c|c|c|c|c|c|c|c|c|}
\hline \multirow{2}{*}{ Flight } & \multirow{2}{*}{$\begin{array}{c}\text { Flight } \\
\text { time }\end{array}$} & \multicolumn{1}{|c|}{$d_{i j}$} & \multicolumn{1}{|c|}{$h_{i j}$} & \multicolumn{5}{|c|}{} \\
\hline & & 1 & 2 & 3 & 4 & 5 & 1 & 2 & 3 & 4 & 5 \\
\hline 1 & 100 & 0 & 600 & 1000 & - & - & 5 & 605 & 1005 & - & - \\
\hline 2 & 150 & 400 & 1150 & - & - & - & 405 & 1155 & - & - & - \\
\hline 3 & 180 & 0 & 300 & 700 & 950 & - & 5 & 305 & 705 & 955 & - \\
\hline 4 & 120 & 0 & 350 & 800 & 900 & 1300 & 5 & 355 & 805 & 905 & 1305 \\
\hline 5 & 110 & 450 & 1200 & - & - & - & 455 & 1205 & - & - & - \\
\hline 6 & 200 & 200 & 550 & 650 & - & - & 205 & 555 & 655 & - & - \\
\hline 7 & 180 & 600 & - & - & - & - & 605 & - & - & - & - \\
\hline 8 & 100 & 150 & 340 & 900 & - & - & 155 & 345 & 905 & 0 & 0 \\
\hline 9 & 130 & 500 & 1100 & - & - & - & 505 & 1105 & - & - & - \\
\hline 10 & 160 & 1300 & - & - & - & - & 1305 & - & - & - & - \\
\hline 11 & 90 & 0 & 250 & 350 & 450 & 650 & 5 & 255 & 355 & 455 & 655 \\
\hline 12 & 195 & 180 & 620 & 850 & - & - & 185 & 625 & 855 & - & - \\
\hline 13 & 120 & 860 & 1050 & 1200 & 1350 & - & 865 & 1055 & 1205 & 1355 & - \\
\hline 14 & 140 & 1260 & 1320 & 1400 & - & - & 1265 & 1325 & 1405 & - & - \\
\hline 15 & 115 & 50 & 230 & 300 & 450 & 520 & 55 & 235 & 305 & 455 & 525 \\
\hline 16 & 175 & 90 & 470 & 830 & 1370 & - & 95 & 475 & 835 & 1375 & - \\
\hline 17 & 95 & 490 & - & - & - & - & 495 & - & - & - & - \\
\hline 18 & 135 & 360 & 480 & 1230 & - & - & 365 & 485 & 1235 & - & - \\
\hline
\end{tabular}

second group the length was 10 minutes and for the third group 15 minutes. Please note that all the values are expressed in minutes with beginning at midnight. That means, for example, 6:30 is expressed as 390 minutes.

For each group of the experiments 13 optimisation calculations were carried out; the calculations differed in the number of the planned flights - each group of the experiments was started with 6 flights and ended with 18 flights. For all the optimisation calculations we observed the calculation time.

\subsection{Results of the experiments}

Within the experimental part 39 optimisation calculations were carried out. Table 2 presents results of the experiments for which the length of the time slots was 5 minutes. Table 3 summarises results for 10-minute time slots and Table 4 for 15-minute time slots. Each table consists of three columns. The first column gives information about the number of the flights that have to be served. The second column shows orders in which the planned flights should be served. And finally, the third column presents how many aircraft we need to serve all the planned flights. One can notice that in the tables results for 18 flights are missing. That is because for 18 flights the limitations of the student (demo) version of Xpress-IVE were exceeded; the limitations are given by the maximum number of constants and constraints.
Results of experiments for 5-minute time slots

Table 2

\begin{tabular}{|c|c|c|}
\hline Number of flights & Order of flights & Number of aircraft \\
\hline 6 & $\begin{array}{l}0-1-6 \\
0-3-5-4-2\end{array}$ & 2 \\
\hline 7 & $\begin{array}{l}0-1-5-6-3-4 \\
0-7-2\end{array}$ & 2 \\
\hline 8 & $\begin{array}{l}0-1-5-6-8-2 \\
0-3-7-4\end{array}$ & 2 \\
\hline 9 & $\begin{array}{l}0-1-6-9-4-5 \\
0-3-7-8-2\end{array}$ & 2 \\
\hline 10 & $\begin{array}{l}0-3-2-1-4-9-10 \\
0-6-7-8-5\end{array}$ & 2 \\
\hline 11 & $\begin{array}{l}0-3-11-7-4-9-10 \\
0-8-2-6-1-5\end{array}$ & 2 \\
\hline 12 & $\begin{array}{l}0-1-12-7-4-2 \\
0-3-11-5-6-8-9-10\end{array}$ & 2 \\
\hline 13 & $\begin{array}{l}0-1-2-3-5 \\
0-8-4-7-13-9 \\
0-12-11-6-10\end{array}$ & 3 \\
\hline 14 & $\begin{array}{l}0-3-8-9-12-10 \\
0-4-7-1-5 \\
0-11-6-13-2-14\end{array}$ & 3 \\
\hline
\end{tabular}


Results of experiments for 5-minute time slots

\begin{tabular}{|l|l|c|}
\hline 15 & $\begin{array}{l}0-1-12-5-6-3-10 \\
0-8-9-4-2 \\
0-15-11-7-13-14\end{array}$ & 3 \\
\hline \multirow{2}{*}{16} & $0-3-11-7-13-2-14$ & 3 \\
& $0-4-6-15-8-9-10$ & \\
& $0-16-1-12-5$ & \\
\hline 17 & $0-1-8-15-6-3-5$ & 3 \\
& $0-12-17-11-13-9-10$ & \\
\hline
\end{tabular}

Results of experiments for 10-minute time slots

Table 3

\begin{tabular}{|c|c|c|}
\hline Number of flights & Order of flights & Number of aircraft \\
\hline 6 & $\begin{array}{l}0-1-4-2 \\
0-6-3-5\end{array}$ & 2 \\
\hline 7 & $\begin{array}{l}0-4-2-6-1-5 \\
0-7-3\end{array}$ & 2 \\
\hline 8 & $\begin{array}{l}0-1-5-3-2 \\
0-6-7-8-4\end{array}$ & 2 \\
\hline 9 & $\begin{array}{l}0-1-3-7-8-2 \\
0-6-9-4-5\end{array}$ & 2 \\
\hline 10 & $\begin{array}{l}0-1-8-7-4-9-10 \\
0-6-5-3-2\end{array}$ & 2 \\
\hline 11 & $\begin{array}{l}0-1-6-5-3-2 \\
0-8-11-7-4-9-10\end{array}$ & 2 \\
\hline 12 & $\begin{array}{l}0-1-12-7-4-5 \\
0-3-11-2-6-8-9-10\end{array}$ & 2 \\
\hline 13 & $\begin{array}{l}0-1-7-8-2 \\
0-4-3-6-9 \\
0-11-12-5-13-10\end{array}$ & 3 \\
\hline 14 & $\begin{array}{l}0-1-12-5-11-8-10 \\
0-2-6-3-4 \\
0-7-13-9-14\end{array}$ & 3 \\
\hline 15 & $\begin{array}{l}0-4-6-7-3-10 \\
0-11-12-9-8-5 \\
0-15-2-1-13-14\end{array}$ & 3 \\
\hline 16 & $\begin{array}{l}0-3-2-1-16-5-14 \\
0-6-7-13-10 \\
0-11-8-15-12-9-4\end{array}$ & 3 \\
\hline 17 & $\begin{array}{l}0-3-5-6-1-10 \\
0-11-8-15-17-12-2-14 \\
0-16-7-13-9-4\end{array}$ & 3 \\
\hline
\end{tabular}

Results of experiments for 15-minute time slots

\begin{tabular}{|c|c|c|}
\hline Number of flights & Order of flights & Number of aircraft \\
\hline 6 & $\begin{array}{l}0-1-4-6 \\
0-2-3-5\end{array}$ & 2 \\
\hline 7 & $\begin{array}{l}0-1-4-7-5 \\
0-3-2-6\end{array}$ & 2 \\
\hline 8 & $\begin{array}{l}0-1-8-7-4-5 \\
0-6-3-2\end{array}$ & 2 \\
\hline 9 & $\begin{array}{l}0-1-7-8-2 \\
0-3-5-6-9-4\end{array}$ & 2 \\
\hline 10 & $\begin{array}{l}0-1-6-7-8-5 \\
0-4-2-3-9-10\end{array}$ & 2 \\
\hline 11 & $\begin{array}{l}0-3-2-6-1-5 \\
0-8-11-7-4-9-10\end{array}$ & 2 \\
\hline 12 & $\begin{array}{l}0-1-8-4-7-12-2 \\
0-11-6-5-3-9-10\end{array}$ & 2 \\
\hline 13 & $\begin{array}{l}0-1-8-5-6-4-9-10 \\
0-3-11-7-12-2-13\end{array}$ & 2 \\
\hline 14 & $\begin{array}{l}0-1-6-4-5-14 \\
0-11-8-2-3-9-10 \\
0-12-7-13\end{array}$ & 3 \\
\hline 15 & $\begin{array}{l}0-1-12-5-13-9-14 \\
0-11-6-8-10 \\
0-15-3-7-4-2\end{array}$ & 3 \\
\hline 16 & $\begin{array}{l}0-4-15-7-12-16 \\
0-8-2-1-5-14 \\
0-11-6-9-3-13-10\end{array}$ & 3 \\
\hline 17 & $\begin{array}{l}0-1-12-7-4-9-10 \\
0-3-11-15-16-2-13 \\
0-6-17-8-5-14\end{array}$ & 3 \\
\hline
\end{tabular}

Fig. 1 The dependence of the calculation times on the number of the flights and the length of the time slots

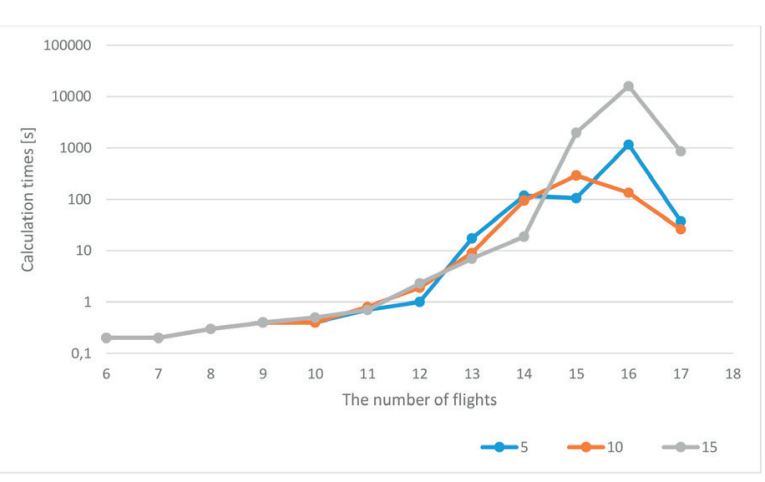

Table 5 and Fig. 1 summarise results of the experiments as regards the dependence of the calculation time (in seconds) on the number of the flights and the length of the time slots. Please note that the length of the time slots is expressed in minutes in Table 5 and the calculation times in seconds. Due to large range 
Results of experiments - calculation times (in seconds) Table 5

\begin{tabular}{|c|c|c|c|c|c|c|c|c|c|c|c|c|}
\hline Time slot length & \multicolumn{10}{|c|}{ Number of flights } \\
\hline & 6 & 7 & 8 & 9 & 10 & 11 & 12 & 13 & 14 & 15 & 16 & 17 \\
\hline 5 & 0.2 & 0.2 & 0.3 & 0.4 & 0.4 & 0.7 & 1.0 & 17.3 & 118.6 & 105.1 & 1162.2 & 37.2 \\
\hline 10 & 0.2 & 0.2 & 0.3 & 0.4 & 0.4 & 0.8 & 1.9 & 9.0 & 93.9 & 290.7 & 133.0 & 26.0 \\
\hline 15 & 0.2 & 0.2 & 0.3 & 0.4 & 0.5 & 0.7 & 2.3 & 7.0 & 18.8 & 1972.8 & 15943.5 & 851.7 \\
\hline
\end{tabular}

of the calculation times the logarithmical scale is used for the vertical axis of Fig. 1.

\section{Conclusions}

The presented article is devoted to planning flight timetables for charter airlines using mathematical modelling. In the paper the mathematical model that enables to plan flights in situations where due to capacity limitations at the airport the time slots for serving the flights are applied. The model is universal in terms of the number of the time slots. That means the individual flights can have different numbers of the possible time slots.

The calculation experiments carried out with model were focused on the calculation times needed to get an optimal the experiments the number of the planned flights and the length of the time slots were changed. The length of the time slots was assumed equal to 5,10 and 15 minutes and the number of the flights was equal from 6 up to 17. For 18 flights the limitations of the academic (demo) version of Xpress-IVE were exceeded.

In our future research we would like to implement some other constraints following from real operation. We can mention, for example, a more detailed analysis of times needed for doing the tasks connected with aircraft services or planning maintenance of the aircraft. Our next target is to test the model in full version of optimisation software Xpress-IVE in order to find out calculation limits for the number of the planned flights.

\section{References}

[1] GRAF, V., TEICHMANN, D., DORDA, M.: Mathematical Model of Charter Flight Scheduling with Predefined Time Slots. Proc. of international conference Aplimat, February 2016, Bratislava, pp. 417-423, ISBN 978-80-4531-4.

[2] DOZIC, S., KALIC, M., BABIC, O.: Heuristic Approach to the Airline Schedule Disturbances Problem: Single Fleet Case. Social and Behavioral Science, vol. 54, 2012, pp. 1232-1241.

[3] BASDERE, M., BILGE, U.: Operational Aircraft Maintenance Routing Problem with Remaining Time Consideration. European J. of Operational Research, vol. 235, 2014, pp. 315-328.

[4] LAGERHOLM, M., PETERSON, C., SODERBERG, B.: Airline Crew Scheduling Using Potts Mean Field Techniques. European J. of Operational Research, vol. 120, 2000, pp. 81-96.

[5] JANACEK, J., MARTON, P., KONIORCZYK, M.: The Column Generation and Train Crew Scheduling. Communications - Science Letters of the University of Zilina, vol. 17, No. 1a, 2016, pp. 21-27.

[6] BARNHART, C., BELOBABA, P., ODONI, A. R.: Applications of Operations Research in the Air Transport Industry. Transportation Science, vol. 37, No. 4, 2003, pp. 368-391.

[7] DIAZ-RAMIREZ, J., HUERTAS, J. I., TRIGOS, F.: Aircraft Maintenance, Routing and Crew Scheduling Planning for Airlines with a Single Fleet and a Single Maintenance and Crew Base. Computers \& Industrial Engineering, vol. 75, 2014, pp. $68-78$.

[8] MERCIER, A., SOUMIS, F.: An Integrated Aircraft Routing, Crew Scheduling and Flight Retiming Model. Computers \& Operations Research, vol. 34, 2007, p. 2251-2265.

[9] KERNER, L., KULCAK, L., SYKORA, V.: Operational Aspects of Airports (in Czech), Praha : CVUT, 2003, 270 p., ISBN 80-0102841-0.

[10] FAIR ISAAC CORPORATIN, [online], (C2014 [11-2-2016]. http://www.fico.com/en/products/fico-xpress-optimization-suite/. 